\title{
Structural and Electronic Characterization of $\mathrm{Cu}_{\mathrm{x}} \mathrm{Bi}_{2} \mathrm{Se}_{3}$
}

\section{Paola Arévalo López, ${ }^{*}$ Francisco Morales Leal and Roberto Escudero Derat}

Instituto de Investigaciones en Materiales, Universidad Nacional Autónoma de México, Ciudad Universitaria, 04510, México, D.F., México.

* Tel: (+52) 55562246 25. Email: paola.arevalo@iim.unam.mx

Received November 25 ${ }^{\text {th }}, 2015$; Accepted May $13^{\text {th }}, 2016$.

\begin{abstract}
Topological insulator $\mathrm{Bi}_{2} \mathrm{Se}_{3}$ becomes superconductor when it is intercalated with copper. In this work, we present our studies related to the electronic and structural characterization of $\mathrm{Cu}_{\mathrm{x}} \mathrm{Bi}_{2} \mathrm{Se}_{3}$ with $\mathrm{Cu}$ variation from $\mathrm{x}=0.11$ to 0.20 . We show structural and chemical studies performed via X-ray diffraction and photoelectron spectroscopy. $\mathrm{Cu}$ insertion modifies the $\mathrm{Bi}$ and Se binding energies and induces superconductivity in the compound.
\end{abstract}

Key words: Thermoelectric materials; bismuth chalcogenides; superconductivity.

\section{Introduction}

In the last decade, thermoelectric materials have been widely investigated due to their potential applications in different processes: recovering of residual heat, refrigeration, heating, and generation of clean energy, without moving parts [1]. A good thermoelectric material, suitable for applications, must have a high figure of merit $(\mathrm{ZT}>1)$ defined as: $Z T=\frac{\sigma S^{2}}{\kappa} T$, where $\mathrm{S}$ is the Seebeck coefficient, $\sigma$ is the electrical conductivity, $\kappa$ the total thermal conductivity, and $\mathrm{T}$ the temperature [2].

Bismuth chalcogenides $\mathrm{Bi}_{2} \mathrm{M}_{3}(\mathrm{M}=\mathrm{S}, \mathrm{Se}, \mathrm{Te})$ have layered structures that present good electrical and poor thermal conductivity $[3,4]$ therefore they are good for thermoelectric devices. Moreover, it has been discovered that they present topological insulator behavior and superconductivity [5-8].

Among thermoelectric materials, bismuth tellurides $\left(\mathrm{Bi}_{2} \mathrm{Te}_{2.7} \mathrm{Se}_{0.3}\right.$ and $\left.\mathrm{Bi}_{0.5} \mathrm{Sb}_{1.5} \mathrm{Te}_{3}\right)$ are the most studied compounds because ZT may reach values of 1 at room temperature [9]. $\mathrm{Bi}_{2} \mathrm{Se}_{3}$ is a narrow band gap material, which is used as solid-state cooler or generator, as well as a spintronic device when considered as a topological insulator [10-12].

$\mathrm{Bi}_{2} \mathrm{Se}_{3}$ crystallizes in a rhombohedral structure (space group R-3m, with parameters: $\mathrm{a}=4.143 \AA$, and $\mathrm{c}=28.636 \AA$, Fig. 1a). The structure can be described as a layered structure, formed by three double-layers of edge-sharing $\mathrm{BiSe}_{6}$ octahedra (Fig. 1b) stacked along the [001] direction, equivalent to the Se1-Bi-Se2-Bi-Se1 quintuple layers as often referred in the literature $[13,14]$. These double-layers are weakly bonded via van der Waals interactions, resulting in an easy cleavage material [13].
Resumen. El aislante topológico $\mathrm{Bi}_{2} \mathrm{Se}_{3}$ se vuelve superconductor cuando en él se intercala cobre. En este trabajo presentamos estudios relacionados con la caracterización electrónica y estructural de $\mathrm{Cu}_{\mathrm{x}} \mathrm{Bi}_{2} \mathrm{Se}_{3}$ con variaciones de $\mathrm{Cu}$ desde $\mathrm{x}=0.11$ hasta 0.20 . Los resultados estructurales y químicos han sido obtenidos mediante estudios de difracción de rayos X y espectroscopia de fotoelectrones. La inserción de $\mathrm{Cu}$ modifica las energías de enlace de $\mathrm{Bi}$ y Se, induciendo superconductividad en el compuesto.

Palabras clave: Materiales termoeléctricos; calcogenuros de bismuto; superconductividad.
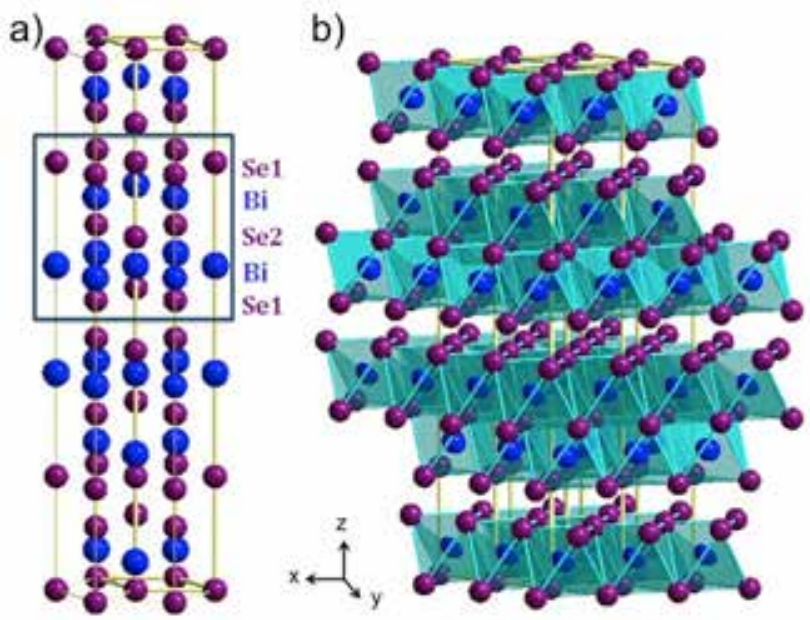

Fig. 1. a) Crystal structure of $\mathrm{Bi}_{2} \mathrm{Se}_{3}$, consisting of stacked quintuple layers, in the order Se1-Bi-Se2-Bi-Se1. b) Double layers of $\mathrm{BiSe}_{6}$ octahedra.

$\mathrm{Bi}_{2} \mathrm{Se}_{3}$ may accept many chemical modifications, either by Bi substitution, as in $\mathrm{Bi}_{2-\mathrm{x}-\mathrm{y}} \mathrm{Sb}_{\mathrm{x}} \mathrm{Pb}_{\mathrm{y}} \mathrm{Se}_{3}$ [15]; or by Se substitution, as in $\mathrm{Bi}_{2} \mathrm{Se}_{3}-\mathrm{Bi}_{2} \mathrm{Te}_{3}$, forming a solid solution [13]. Intercalation between the double-layers is also possible and it has been recently reported that doping bismuth selenide with small amounts of copper, $\mathrm{Cu}_{\mathrm{x}} \mathrm{Bi}_{2} \mathrm{Se}_{3}$, results in a superconducting compound [16-18].

In order to elucidate the role that higher doping concentration has on the structure of $\mathrm{Bi}_{2} \mathrm{Se}_{3}$ and its effect on the superconducting and thermoelectric properties we have prepared $\mathrm{Cu}_{\mathrm{x}} \mathrm{Bi}_{2} \mathrm{Se}_{3}$ with $\mathrm{x}=0.11$ to 0.20 we present chemical and 
structural characterization, and the electronic properties of $\mathrm{Cu}_{\mathrm{x}-}$ $\mathrm{Bi}_{2} \mathrm{Se}_{3}$. Superconductivity was characterized via magnetization and resistivity measurements as a function of temperature. The chemical environment of the atoms was probed with X-ray photoelectron spectroscopy for the different compositions.

\section{Results and Discussion}

Samples were prepared as described in the experimental section. The crystal structure was confirmed by X-ray diffraction (Fig. 2), identified by comparison with X-ray patterns of rhombohedral $\mathrm{Bi}_{2} \mathrm{Se}_{3}$ in the Inorganic Crystal Structure Database (ICSD: 04-2545). The obtained patterns show that the crystals are single phase and the sharp reflections indicate their high crystallinity. These reflections correspond to the basal plane $(00 l)$, obeying the expected systematic absences for the R-3m rhombohedral space group and the total preferred orientation of the platelet-like crystals. Le Bail fits to the diffraction data confirm the $\mathrm{Cu}$ insertion with an increase of the c-axis from $\mathrm{c}=$ 28.6495(6) $\AA$, for $\mathrm{Bi}_{2} \mathrm{Se}_{3}$ to $\mathrm{c}=28.7100(7) \AA$, for $\mathrm{Cu}_{0.20} \mathrm{Bi}_{2} \mathrm{Se}_{3}$. The shift of the cell parameter suggests that for high doping levels inter and intra-layer $\mathrm{Cu}$ susbtitution is taking place in $\mathrm{Cu}_{\mathrm{x}} \mathrm{Bi}_{2} \mathrm{Se}_{3}$. The $\mathrm{Cu}$ atoms are incorporated either by $\mathrm{Bi}$ substitution or by intercalation between the double-layers. In the case of $\mathrm{Bi}$ substitution the lattice constant would be smaller due to smaller $\mathrm{Cu}^{+}$ion radius $\left(0.77 \AA, \mathrm{Bi}^{3+}\right.$ radii $\left.=1.03 \AA\right)$. In the case of intercalation between the double-layers there should be an increase in the c-axis lattice constant.

The crystal structure can be seen as alternating layers of bismuth and selenium along the $\mathrm{c}$ direction. The unit cell has three hexagonal "quintuple" layers. The stacking in each quintuple layer occurs in Se1-Bi1-Se2-Bi1-Se1 order, where 1 and 2 refers to different atomic positions as indicated in Fig. 1. Se1 and Bil are located on the $6 \mathrm{c}$ site, $(0,0, z),(z=0.2115$ and

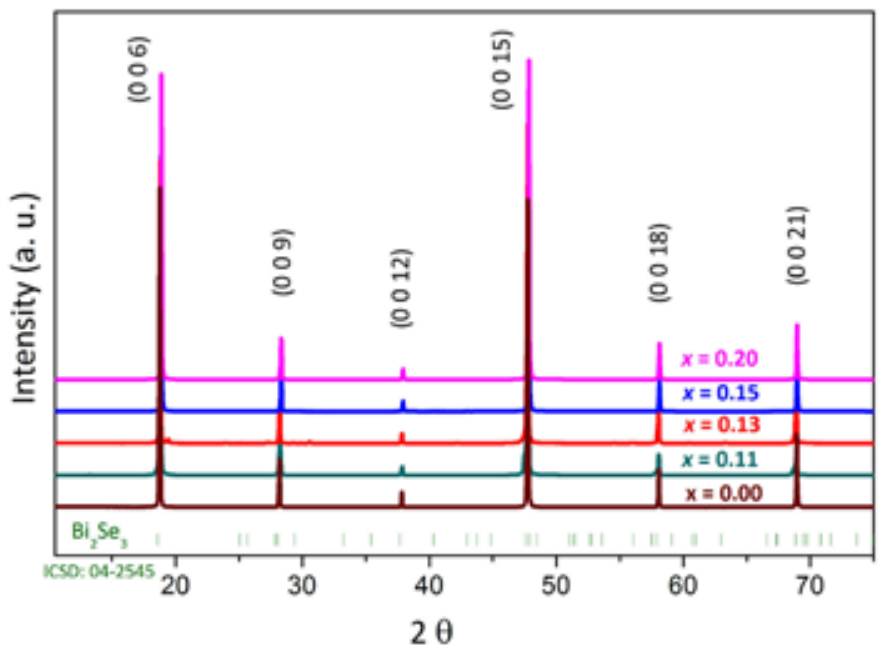

Fig. 2. X-ray diffraction patterns of cleaved single crystals of $\mathrm{Cu}_{\mathrm{x}-}$ $\mathrm{Bi}_{2} \mathrm{Se}_{3}$ at various $\mathrm{Cu}$ concentrations.

0.3985 respectively), and $\mathrm{Se} 2$ on the $3 \mathrm{a}$ site, $(0,0,0)$ [19]. The chemical bonding intra-quintuple-layer has been shown to be covalent, while the bonding inter-quintuple-layer is weak predominantly by van der Waals interactions $[13,20]$. These crystal properties make an easy-to-cleavage material due to its layered nature.

In order to study the surface morphology, scanning electron microscopy (SEM) and energy-dispersive X-ray spectroscopy (EDS) were performed on the different chemical phases and composition.

The back scattering electron (BSE) images show homogeneity in the samples; no segregation or clusters of the dopant were found (Fig. 3a and 3c). As mentioned above the structures are layered due to the crystallographic nature of the bismuth chalcogenides. The EDS spectra indicate that $\mathrm{Bi}, \mathrm{Se}$ and $\mathrm{Cu}$ are the only elements present in the samples, Fig. $3 \mathrm{~b}$ and $3 \mathrm{~d}$.
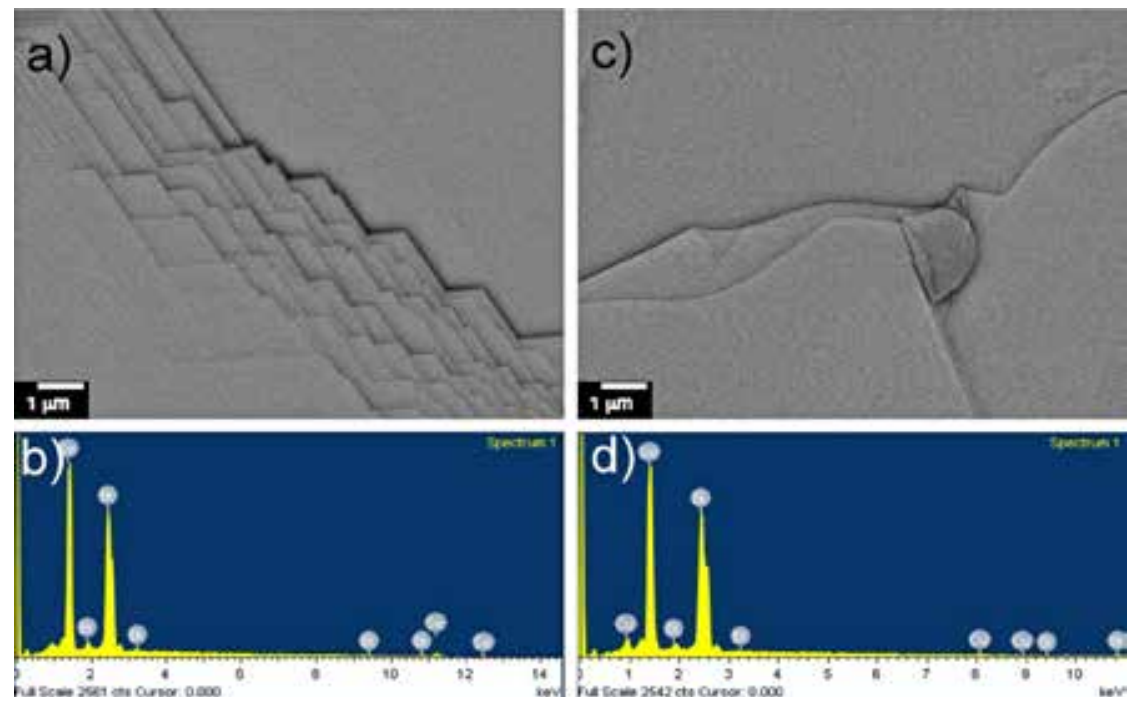

Fig. 3. Backscattered electron images and energy-dispersive $\mathrm{X}$-ray spectroscopy performed on a) and $\mathbf{b}) \mathrm{Bi}_{2} \mathrm{Se}_{3}$ and c) and d) $\mathrm{Cu}_{0.13} \mathrm{Bi}_{2} \mathrm{Se}_{3}$, respectively. 


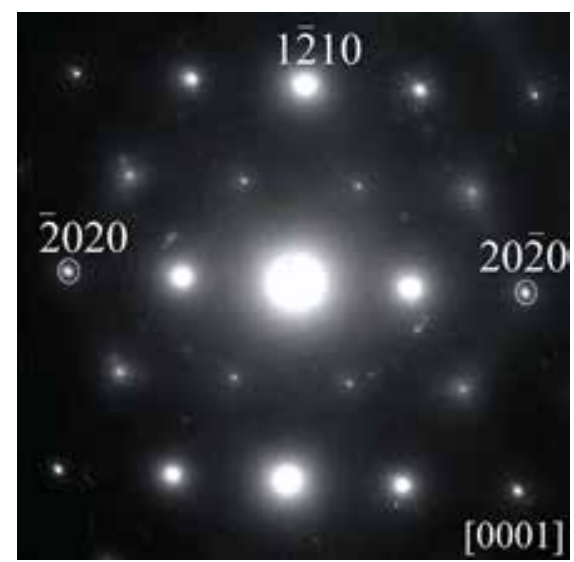

Fig. 4. SAED pattern obtained for $\mathrm{Cu}_{0.15} \mathrm{Bi}_{2} \mathrm{Se}_{3}$ along the $\left[\begin{array}{lll}0 & 0 & 1\end{array}\right]$ zone axis.

Moreover, to confirm any possible superstructure, electron diffraction microscopy was performed. The sample preparation consisted of mechanical exfoliation, in a "graphene-like" manner. The selected area electron diffraction (SAED) pattern shown in Fig. 4 was taken from the $\mathrm{Cu}_{0.15} \mathrm{Bi}_{2} \mathrm{Se}_{3}$ sample, but is representative of all the series. The diffraction pattern is characteristic of a single domain and no diffuse scattering or extra maxima were observed, in contrast with $\mathrm{Cu}_{\mathrm{x}} \mathrm{TiSe}_{2}$ where the $\mathrm{Cu}$ orders in between the layers doubling the a and c parameters [21]. The pattern can be identified as the $\left[\begin{array}{lll}0 & 0 & 1\end{array}\right]$ zone axis projection of the hexagonal $\mathrm{Bi}_{2} \mathrm{Se}_{3}$ reciprocal lattice.

The X-ray photoelectron spectroscopy analyses are shown in Fig. 5, the XPS survey spectra were taken after etching samples for 5 min with $\mathrm{Ar}^{+}$. It is observed that after etching the surface is free of carbon and oxygen. The doped samples also show the characteristic binding energies for $\mathrm{Cu}$ orbitals, indicating that all of them have copper inside.
To understand the role of chemical state via analysis of the binding energy (BE), we performed high-resolution XPS spectra core level for the $\mathrm{Bi} 4 f$, $\mathrm{Bi} 5 d$, Se $3 d$ and $\mathrm{Cu} 2 p$ orbitals, Fig. 6. The energy ranges corresponding to the Bi $4 f$ and $\mathrm{Bi} 5 d$ orbitals are shown in Fig. 6a and 6b, respectively. It is observed that the $\mathrm{Cu}_{\mathrm{x}} \mathrm{Bi}_{2} \mathrm{Se}_{3}$ samples do not have $\mathrm{Bi}$ metal or $\mathrm{Bi}_{2} \mathrm{O}_{3}$ impurities; except for a small amount when $\mathrm{x}=0.11$, where the peaks show a broadening at lower energies indicating that $\mathrm{Bi}$ metal is present. The $\mathrm{BE}$ of $\mathrm{Bi} 5 d_{3 / 2}$ and $\mathrm{Bi} 5 d_{5 / 2}$ are $27.40 \mathrm{eV}$ and $24.30 \mathrm{eV}$ in $\mathrm{Bi}_{2} \mathrm{Se}_{3}$, respectively. It can be observed that there is a slight shift of the $\mathrm{BE}$ to lower energies for these orbitals with the insertion of copper in the samples; which could be explained if the incorporated copper atoms exist as $\mathrm{Cu}^{+}$ions, in agreement with other reports [22, 23].

The binding energies for the Se $3 d_{3 / 2}$ and Se $3 d_{5 / 2}$ orbitals are very close, Fig. $6 \mathrm{c}$. The binding energy ranges for the $\mathrm{Cu}$ $2 p_{1 / 2}$ and $\mathrm{Cu} 2 p_{3 / 2}$ orbitals, depicted in Fig. 6d, show that copper is present as copper ions $\mathrm{Cu}^{+}$in all the doped samples.

The magnetic susceptibility $\chi$ of all the doped samples measured at $10 \mathrm{Oe}$ in the temperature range from 2 to $8 \mathrm{~K}$ are shown in Fig. 7. These data show that all doped samples are superconducting, with a $\mathrm{T}_{\mathrm{c} \text { onset }}$ of $3.4 \mathrm{~K}$ for $\mathrm{x}=0.13$, in agreement with other reports $[16,18,23]$.

Resistance measurements were performed from 300 to $2 \mathrm{~K}$. They show a metallic behavior (Fig. 8). The samples with composition $\mathrm{x}=0.15$ and $\mathrm{x}=0.20$ show a drop in the resistance, at the same temperature where the diamagnetic behavior appears, but the resistance does not drop to zero, indicating that the amount of superconducting material is quite small and the percolation limit is not reached. This observation is indicative of no bulk superconductivity. The ratio of the resistance from room temperature to about $4 \mathrm{~K}$ is small.

In addition we performed thermoelectric properties measurements; Seebeck coefficient $S$, resistivity $(\rho=1 / \sigma)$, and

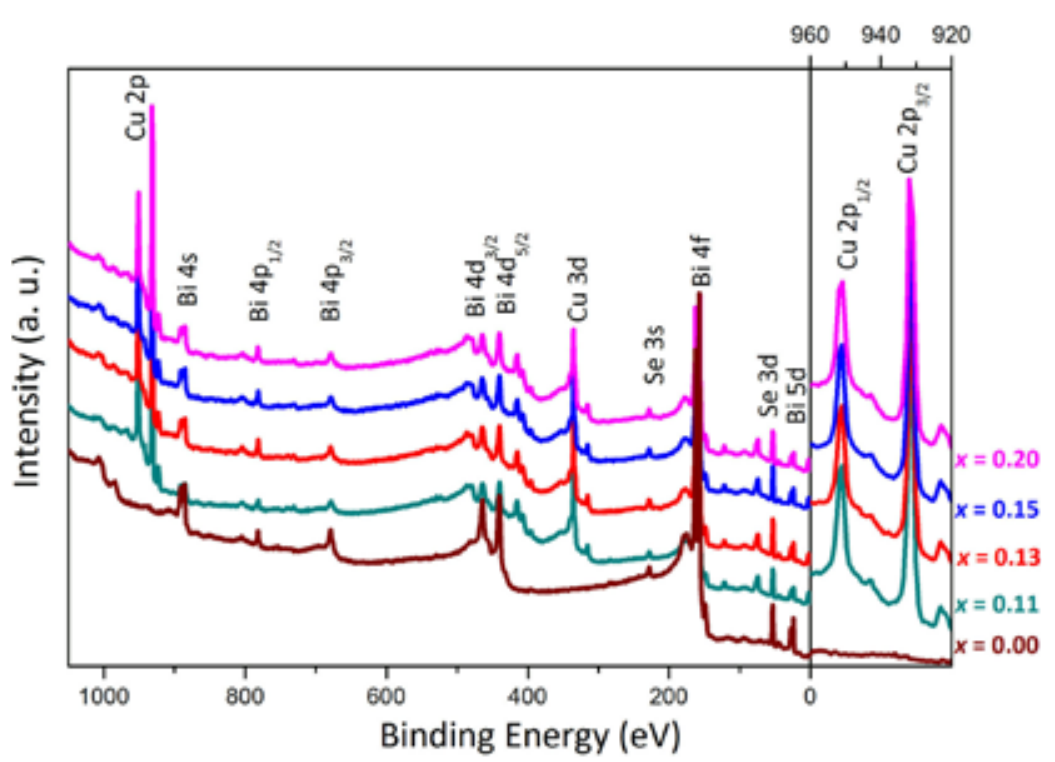

Fig. 5. X-ray photoelectron spectroscopy spectra of $\mathrm{Cu}_{\mathrm{x}} \mathrm{Bi}_{2} \mathrm{Se}_{3}$ samples. Right side shows an enlargement of $\mathrm{Cu} 2 p$ orbital. 

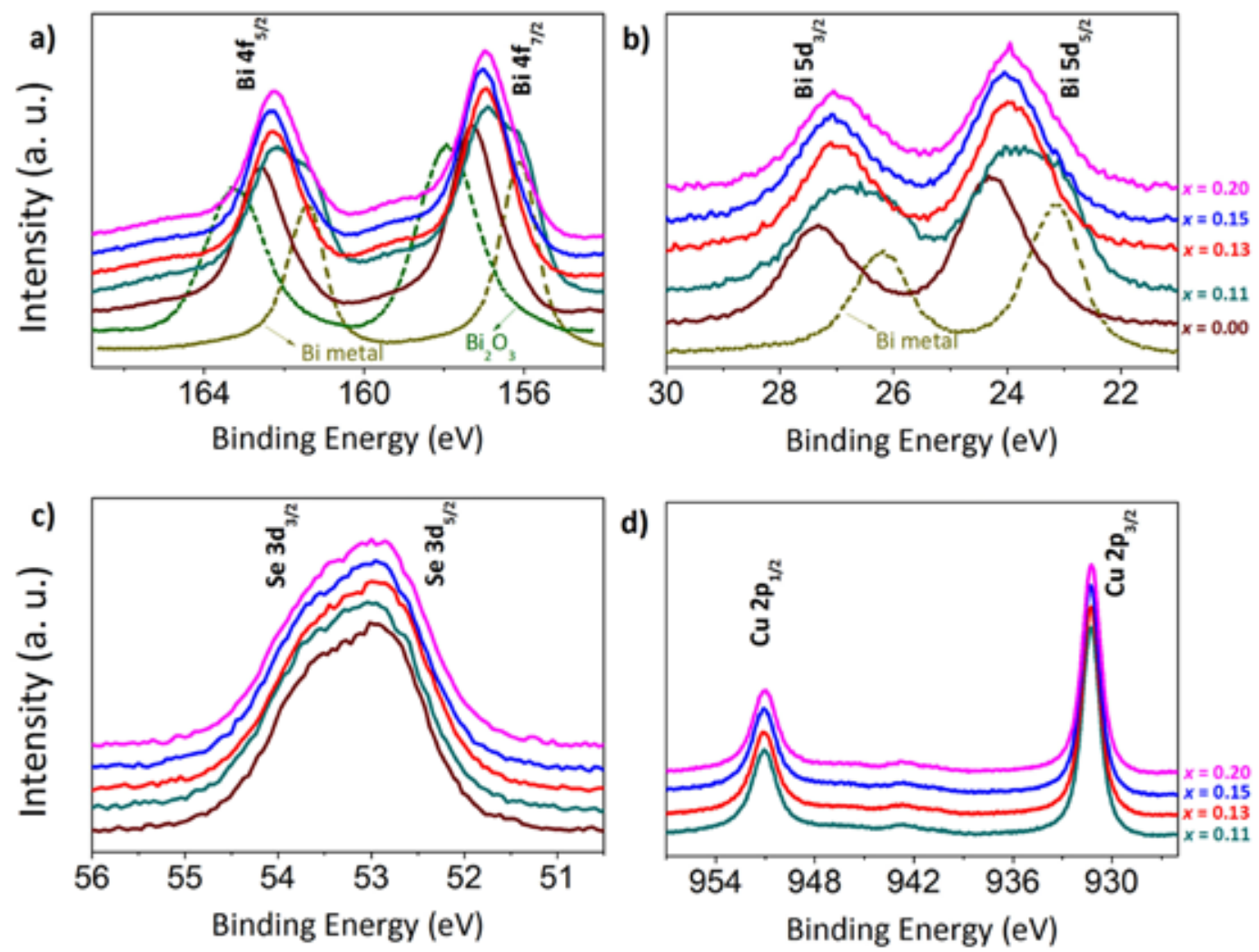

Fig. 6. High-resolution XPS spectra for the orbitals: a) Bi $4 f$, b) Bi $5 d$, c) Se $3 d$, and d) $\mathrm{Cu} 2 p$.

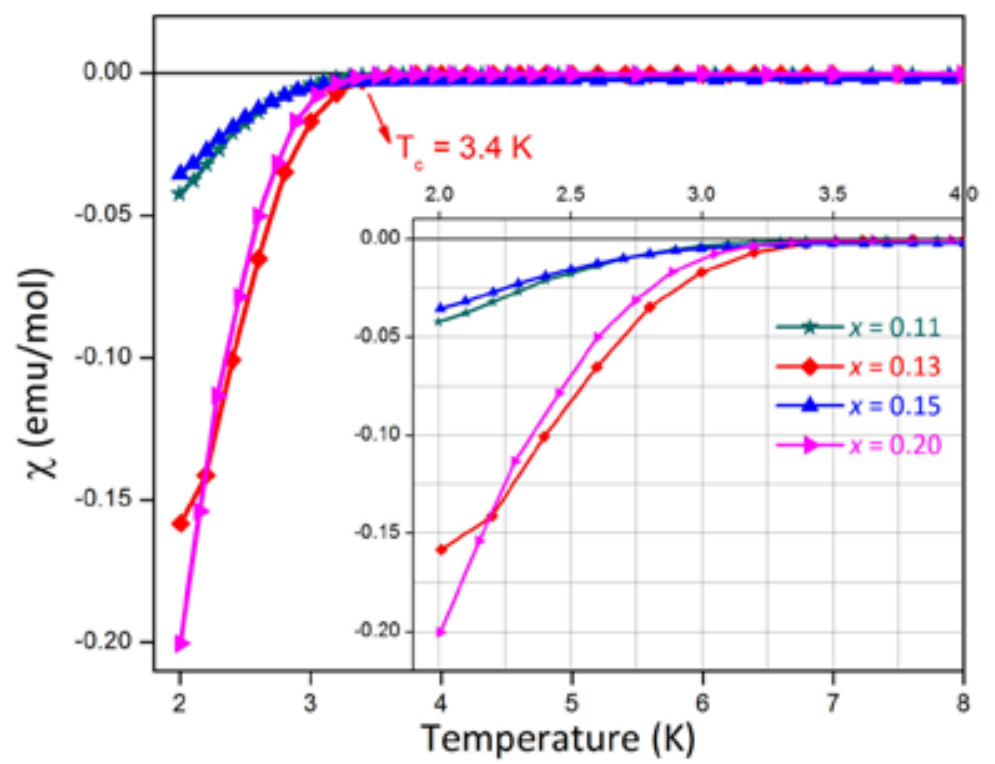

Fig. 7. Susceptibility as a function of temperature, from 2 to $8 \mathrm{~K}$ at an applied field $\mathrm{H}=10$ Oe. Note that the diamagnetic behavior indicates a $\mathrm{T}_{\mathrm{c}}=3.4 \mathrm{~K}$. The inset shows a close view from $2 \mathrm{~K}$ to $4 \mathrm{~K}$.

thermal conductivity $\kappa$. In order to obtain a good thermoelectric material it is necessary to have high values of $\mathrm{S}$ and $\sigma$, which implies a low resistivity value, and the lowest $\kappa$ possible, resulting in a high $\mathrm{ZT}$ value. Therefore, we compare the thermoelectric properties of $\mathrm{Cu}_{0.15} \mathrm{Bi}_{2} \mathrm{Se}_{3}, \mathrm{Cu}_{0.20} \mathrm{Bi}_{2} \mathrm{Se}_{3}$ and $\mathrm{Bi}_{2} \mathrm{Se}_{3} ;$ Fig. 9 shows the differences between these compounds. These results show that when doping bismuth selenide with copper the Seebeck coefficient is diminished, the thermal conductivity decreases its value at low temperature $(2-100 \mathrm{~K})$ and the resistivity has no significant modification. Accordingly, the figure of merit drops 


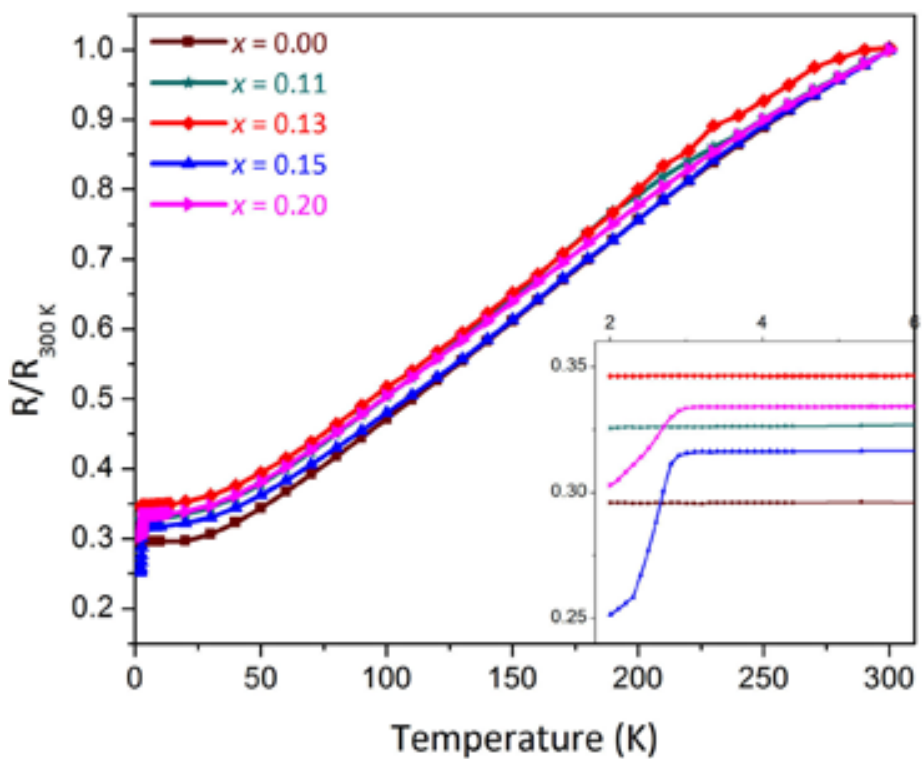

Fig. 8. Resistance measurements in the temperature range from 300 to $2 \mathrm{~K}$, normalized at $300 \mathrm{~K}$. The inset shows the low temperature region where the drop in the resistance for $\mathrm{x}=0.15$ and $\mathrm{x}=0.20$ can be clearly observed.

down to zero in all the temperature range measured, resulting in a material with poor thermoelectric properties for applications in the temperature region studied. The apparent semiconductor behavior observed for $\mathrm{x}=0.20$ in resistivity data (Fig. 9a) is probably due to non-ohmic contact resistance. It is worth noting that in the analogue compound $\mathrm{Cu}_{\mathrm{x}} \mathrm{Bi}_{2} \mathrm{Te}_{3}$, the thermoelectric properties are improved with the insertion of $\mathrm{Cu}$ nanoparticles [24], which is opposed to what we observed in $\mathrm{Cu}_{\mathrm{x}} \mathrm{Bi}_{2} \mathrm{Se}_{3}$.

Ideally, one would like to have independence between the electrical and the thermal transport, and that is the success on
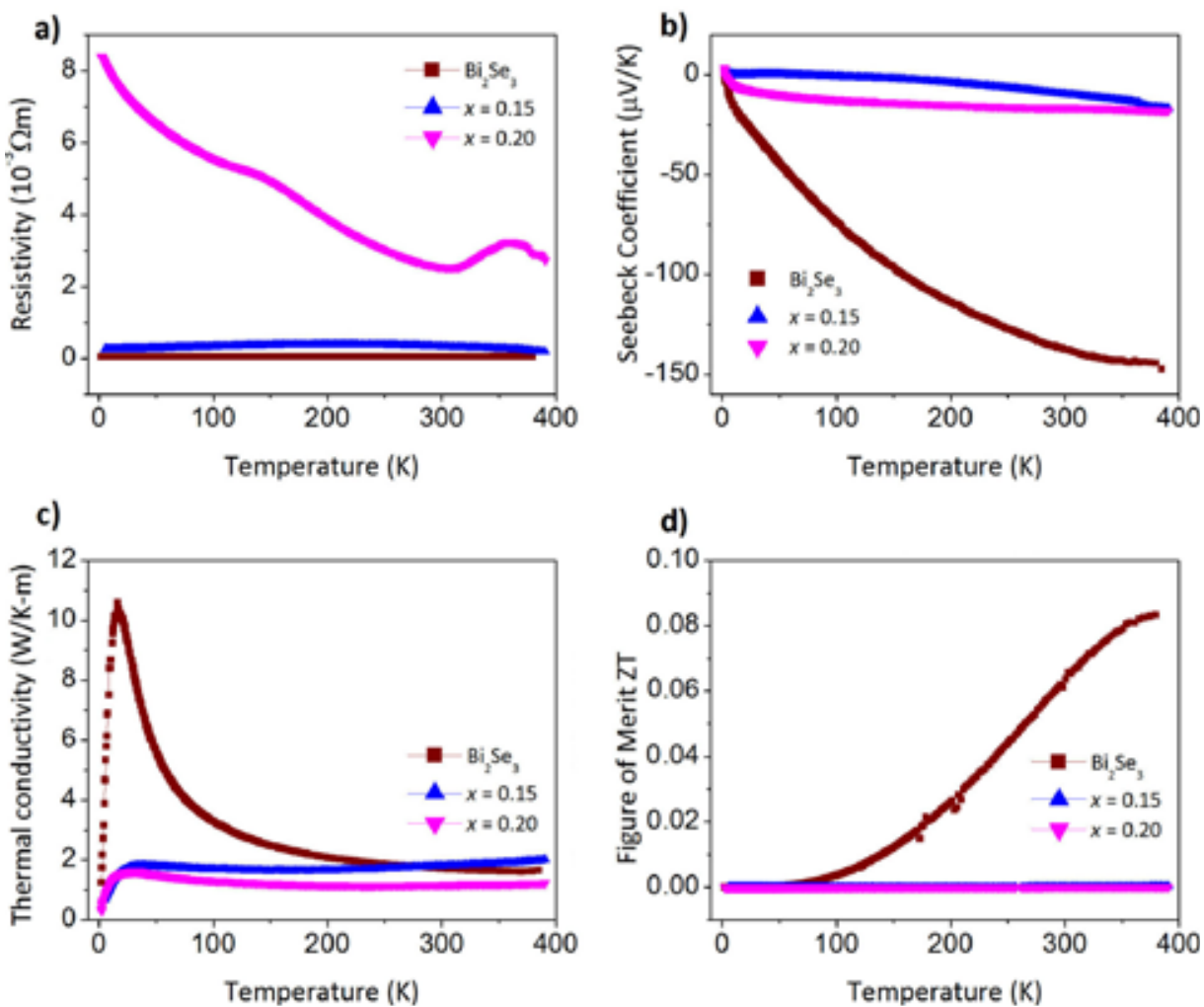

Fig. 9. Thermoelectric properties of $\mathrm{Bi}_{2} \mathrm{Se}_{3}$ and $\mathrm{Cu}_{\mathrm{x}} \mathrm{Bi}_{2} \mathrm{Se}_{3}$, the measurements were recorded in the temperature range from 390 to $2 \mathrm{~K}$. 
the use of layered compounds as thermoelectric materials, their structure favors this independence [25]. At first glance, copper doping on $\mathrm{Bi}_{2} \mathrm{Se}_{3}$ looks like a naive approach in order to reach a high ZT value, since its metallic character will increase both electrical and thermal transport. However, if $\mathrm{Cu}$ is just inserted (inter-quintuple-layer) and not substituted (intra-quintuple-layer), i.e. keeping an independence between $a b$-plane and $c$-axis, the electrical transport will be increased along the $a b$-plane but with a big anisotropy regarding the $c$-axis, and vice versa for the thermal transport. XPS results show a reduction on the Bi binding energy, which increases with $\mathrm{Cu}$ insertion; this is due to a change on the bismuth chemical environment (intra-quintuple-layer). Therefore, we propose that both intercalation and substitution are present in $\mathrm{Cu}_{\mathrm{x}} \mathrm{Bi}_{2} \mathrm{Se}_{3}$, resulting in a decrement of the thermoelectric transport values as the $\mathrm{Cu}$ content increases.

\section{Conclusions}

In summary we have studied the system $\mathrm{Cu}_{\mathrm{x}} \mathrm{Bi}_{2} \mathrm{Se}_{3}$ with $\mathrm{x}=0.11$ to 0.20 . X-ray and electron diffraction confirm the crystallinity and crystallographic orientation of the compounds. SEM images show homogeneity in the surface morphology. The chemical analyses (XPS) indicate that $\mathrm{Cu}$ is present as $\mathrm{Cu}^{+}$in doped $\mathrm{Bi}_{2} \mathrm{Se}_{3}$. $\mathrm{Bi} 4 f$ and $5 d$ orbitals, as well as $\mathrm{Se} 3 d$ on the doped samples show a similar chemical environment as in $\mathrm{Bi}_{2} \mathrm{Se}_{3}$ sample, although there is a slight displacement on the $\mathrm{Bi}_{2} \mathrm{Se}_{3}$ binding energy of $\mathrm{Bi}$ and Se orbitals due to copper insertion.

Magnetization measurements indicate that all the doped compounds are superconductors with a $T_{c}$ onset $=3.4 \mathrm{~K}$. Nevertheless, the thermoelectric properties values are reduced due to copper intercalation. Chemical and electronic properties are modified by the incorporation of small amounts of $\mathrm{Cu}$ and suggest not only intercalation but also substitution on $\mathrm{Bi}_{2} \mathrm{Se}_{3}$.

\section{Experimental}

Stoichiometric amounts of high purity Bi (Sigma-Aldrich 99.999\%), Se (Alfa Aesar 99.999\%) and Cu (Sigma-Aldrich 99.99\%) were ground together, pressed into pellets and sealed in evacuated quartz tubes. The sample was heated $(9 \mathrm{~h})$ to a maximum temperature of $850^{\circ} \mathrm{C}$ and held at that temperature for $24 \mathrm{~h}$. After this procedure samples were slowly cooled to $630^{\circ} \mathrm{C}$ and annealed for $24 \mathrm{~h}$. The last step of the synthesis was the quenching of the tubes into water at room temperature; this was needed for the copper intercalation to occur in between the double octahedral layers. Single crystals were obtained with a platelet-like shape.

The phase identification was done with an X-ray diffractometer Bruker D8 using $\mathrm{Cu}-\mathrm{K} \alpha_{1}(\lambda=1.5406 \AA)$ radiation with a Ni filter, under operating conditions of $30 \mathrm{keV}$ and $30 \mathrm{~mA}$, in a Bragg-Brentano geometry. Surface morphology studies were performed with a scanning electron microscope FEG JEOL-7600F at $15 \mathrm{keV}$ of accelerating voltage equipped with
X-ray energy dispersive analyzer Oxford INCA X-Act. Selected-area electron diffraction (SAED) patterns were obtained in a transmission electron microscope JEOL JEM-1200EX operated at an accelerating voltage of $120 \mathrm{keV}$. X-ray photoelectron spectroscopy analyses were performed in an ultra high vacuum (UHV) system VG-Scientific Microtech Multilab ESCA2000, with $\mathrm{Mg} \mathrm{K} \alpha \mathrm{X}$-ray source $(h v=1253.6 \mathrm{eV})$, and a CLAM4 MCD analyzer. The surface of the samples were etched for 5 min with $3.0 \mathrm{kV} \mathrm{Ar}^{+}$at $0.10 \mu \mathrm{A} \mathrm{mm}^{-2}$. The XPS spectra were obtained at $55^{\circ}$ to the normal surface in the constant pass energy mode (CAE), $\mathrm{E}_{0}=50$ and $20 \mathrm{eV}$ for surface and high resolution narrow scan, respectively. The peak positions were referenced to the background silver $3 d_{5 / 2}$ photopeak at 368.20 $\mathrm{eV}$, having a FWHM of $1.00 \mathrm{eV}$, and $\mathrm{C} 1 s$ hydrocarbon groups in $284.50 \mathrm{eV}$ central peak core level position. The XPS spectra were fitted using the SDP v 4.1 program [26]. The XPS error was based on a detection limit estimated to be $0.1 \%$. For the deconvolution analyses the estimated error was $5 \%$ (i.e. \pm 0.05 $\mathrm{eV}$ ) of uncertain propagation.

Electrical transport and figure of merit measurements were performed in a commercial physical properties measurement system (PPMS, Quantum Design) in the $300-2 \mathrm{~K}$ temperature range. Magnetization measurements were done using a SQUID based magnetometer (MPMS, Quantum Design) from 2 to $8 \mathrm{~K}$ with an applied magnetic field of 10 Oe.

\section{Acknowledgments}

This work was supported by CONACyT (Scholarship number 216073 and Project 129293), BISNANO Scientific Collaboration Project, DGAPA-UNAM (Project IN106014) and, ICYTDF (Project PICCO 11-7). We thank Fís. Lázaro Huerta for his assistance in obtaining the XPS spectra, Dr. Omar Novelo for technical support in SEM images, Ing. Carlos Flores for obtaining TEM micrographs and Dr. Ángel Arévalo-López for his valuable comments.

\section{References}

1. Bell, L. Science 2008, 321, 1457-1461.

2. Ioffe, A. F. Semiconductor Thermoelements and Thermoelectric Cooling. Infosearch, London, 1st edition, 1957.

3. Goldsmid, H. J.; Douglas, R. W. Br. J. Appl. Phys. 1954, 5, 386-390.

4. Goldsmid, H. J. in Recent Trends in Thermoelectric Materials Research I, Vol. 69, Academic Press, New York, 1st edition, 2001.

5. Kane, C.; Mele, E. Phys. Rev. Lett. 2005, 95, 226801.

6. Fu, L.; Kane, C.; Mele, E. Phys. Rev. Lett. 2007, 98, 106803.

7. Zhang, H.; Liu, C. X.; Qi, X. L.; Dai, X.; Fang, Z.; Zhang, S. C. Nat. Phys. 2009, 5, 438-442.

8. Hsieh, D.; Xia, Y.; Qian, D.; Wray, L.; Dil, J. H.; Meier, F.; Osterwalder, J.; Patthey, L.; Checkelsky, J. G.; Ong, N. P.; Fedorov, A. V.; Lin, H.; Bansil, A.; Grauer, D.; Hor, Y. S.; Cava, R. J.; Hasan, M. Z. Nature 2009, 460, 1101-1105.

9. Tritt, T. M.; Subramanian, M. A. Mater. Res. Bull. 2006, 31, 188-194. 
10. Wolf, S. A.; Awschalom, D. D.; Buhrman, R. A.; Daughton, J. M.; von Molnár, S.; Roukes, M. L.; Chtchelkanova, A. Y.; Treger, D. M. Science 2001, 294, 1488-1495.

11. Pesin, D.; MacDonald, A. H. Nat. Mater. 2012, 11, 409-416.

12. Cha, J. J.; Koski, K. J.; Cui, Y. Phys. Status Solidi-R 2013, 7, 15-25.

13. Wiese, J. R.; Muldawer, L. J. Phys. Chem. Solids 1960, 15, 13-16.

14. Zhang, G.; Qin, H.; Teng, J.; Guo, J.; Dai, X.; Fang, Z.; Wu, K. H. Appl. Phys. Lett. 2009, 95, 053114.

15. Zhang, Y.; Chang, C. Z.; He, K.; Wang, L. L.; Chen, X.; Jia, J. F.; Ma, X. C.; Xue, Q. K. Appl. Phys. Lett. 2010, 97, 194102.

16. Hor, Y. S.; Williams, A. J.; Checkelsky, J. G.; Roushan, P.; Seo, J.; Xu, Q.; Zandbergen, H. W.; Yazdani, A.; Ong, N. P.; Cava, R. J. Phys. Rev. Lett. 2010, 104, 057001.

17. Wray, L. A.; Xu, S.-Y.; Xia, Y.; Hor, Y. S.; Qian, D.; Fedorov, A. V.; Lin, H.; Bansil, A.; Cava, R. J.; Hasan, M. Z. Nat. Phys. 2010 , 6, 855-859.

18. Hor, Y. S.; Checkelsky, J. G.; Qu, D.; Ong, N. P.; Cava, R. J. J. Phys. Chem. Solids 2011, 72, 572-576.
19. Feutelais, Y.; Legendre, B.; Rodier, N.; Agafonov, V. Mater. Res. Bull. 1993, 28, 591-596.

20. Mishra, S. K.; Satpathy, S.; Jepsen, O. J. Phys.: Condens. Matter 1997, 9, 461-470.

21. Morosan, E.; Zandbergen, H. W.; Dennis, B. S.; Bos, J. W. G.; Onose, Y.; Klimczuk, T.; Ramirez, A. P.; Ong, N. P.; Cava, R. J. Nat. Phys. 2006, 2, 544-550.

22. Kriener, M.; Segawa, K.; Ren, Z.; Sasaki, S.; Wada, S.; Kuwabata, S.; Ando, Y. Phys. Rev. B 2011, 84, 054513.

23. Sasaki, S.; Kriener, M.; Segawa, K.; Yada, K.; Tanaka, Y.; Sato, M.; Ando, Y. Phys. Rev. Lett. 2011, 107, 217001.

24. Han, M.-K.; Ahn, K.; Kim, H. J.; Rhyee, J.-S.; Kim, S.-J. J. Mater. Chem. 2011, 21, 11365-11370.

25. Li, J. F.; Liu, W. S.; Zhao, L. D.; Zhou, M. NPG Asia Mater. 2010 , 2, 152-158.

26. 2004 sdp v4.1 (32bit). Copyright XPS International, LLC, Compiled 17 January 2004. 